\title{
Screening of Low Density Polyethylene Degrading Microflora From Garbage Soil
}

\author{
Kalyani P. Patinge, S. N. Zodpe
}

P. G. Department of Microbiology, Shri Shivaji College of Arts, Commerce and Science, Akola, Maharashtra, India

\section{Article Info}

Volume 7, Issue 4

Page Number: 110-116

Publication Issue :

July-August-2020

\section{Article History}

Accepted : 20 July 2020

Published : 27 July 2020

\section{ABSTRACT}

Plastics have been widely use as a packing material in the form of low density polyethylene. Continuous accumulation of plastic in the environment can cause threat to humidity and environment. In order to stop the accumulation of plastic and to make the surroundings free from plastic, microbes were isolated from medicinal plant soil, garden soil, sewage water soil, Agricultural Soil. These microbes were screened by Clear Zone Technique using polyethylene glycol to confirm the degradation activity. To check the efficiency of biodegradation, weight method was performed under laboratory condition for 2-4 weeks. Experimental data revealed that Pseudomonas species have highest plastic degradation capacityas compared to S.aureus, Bacillus subtilis, $S$. pyogenes, E.coli. in natural and artificial conditions.

Keywords : Low density polyethylene, P.aeruginousa

\section{INTRODUCTION}

Plastics are the synthetic polymers of carbon, hydrogen and oxygen which are derived from petrochemical. About 140 million's tons of synthetic polymers are produced worldwide annually with their utility escalating at a rate of $12 \%$ per annum (Shimao, 2001). Each year, an estimated 500 billion to 1 trillion plastic bags are consumed worldwide (Roy et al., 2008). Low density polyethylene is one of the major sources of environmental pollution. Polythene waste is recognized as a major threat for marine life. Sometimes, it could cause intestinal blockage in the fishs, birds and marine mammals (Spear et al., 1995and Denuncio et al., 2011). Microbial degradation of plastic caused by oxidation or hydrolysis using microbial enzymes that lead to chain cleavage of the high molecular weight into low molecular weight oligomers and monomers by aerobic and anaerobic metabolism. Microbes like Pseudomonas, Streptococcus, Staphylococcus, Micrococcus, Rhodococcus, Bacillus, Brevibacillus, Flavobacterium, Nocardia and Arthrobacter and fungal species Aspergillus niger, Aspergillus glauscus, Cladosporium, Fusarium, Mucor, Penicillium, Phanerochaete and Trichoderma involved in biodegradation of polythene (Kumar et al., 2013; Kathiresan K. 2003; Koutny M. et al., 2006). The biodegradation of LDPE due to the disadvantages of other methods such as cost and pollution. Biodegradation is the ability of microorganism to influence abiotic through physical, chemical or 
enzymatic action (A. C. Albertsson et al., 1987; E. Chiellini et al., 2003)

\section{MATERIALS AND METHOD}

\section{Sample collection :}

Garbage soil sample were collected from plastic contaminated site from Akola district i.e. Akot file, Malkapur, Ramdas peth, khadaki.The soil sample were collected at a depth of $3-5 \mathrm{~cm}$, in sterile containe or paper bagr and then air dried at room temperature.

\section{Isolation of soil bacteria:}

The soil bacteria were isolated by spread technique (Kathiresan, 2003).The $1 \mathrm{gm}$ of Garbage soil sample was taken and mixed in $9 \mathrm{ml}$ of distilled water in a test tube and serially diluted. $0.1 \mathrm{ml}$ aliqout of various dilutions was spread on nutrient agar medium (Himedia, Mumbai) by using pipette and incubated at $37^{\circ} \mathrm{c}$ for $24 \mathrm{hr}$ 's.

\section{Identification of soil bacteria:}

The identification of bacteria was confirmed on the basis of Cultural and Biochemical Characteristics and identified on the basis of Bergey's Manual of Determinative Bacteriology (Holt et al.,1994).

\section{Screening of polyethylene Degrading Microorganisms by Clear ZoneMethod(Augusta et al., 1993):}

Polyethylene Glycol (PEG) was added in mineral salt agar medium at a final concentration of $0.1 \%(\mathrm{w} / \mathrm{v})$ respectively and the mixture was sonicated for $1 \mathrm{hr}$. at $120 \mathrm{rpm}$ in shaker. After this the medium was sterilized at $120^{\circ} \mathrm{C}$ and pressure for $15 \mathrm{lbs} / \mathrm{inch}^{2}$ for 20 min. About $15 \mathrm{ml}$ sterilized medium poured before cooling in each plate. The isolated organism were inoculated at $25-30^{\circ} \mathrm{C}$ for $2-4$ weeks. The organism producing zone of clearance around their colonies were selected for further analysis.

\section{Collection of polythene bags:}

Low density polyethylene bags (LDPE) used in this study was collected from Akola market, which were $20 \mathrm{um}$ in thick in nature. For the experiment, LDPE were cut into small strips of $2 \mathrm{~cm}$ in diameter and they were sterilized with $70 \%$ ethanol, air dried and weighed to check initial weight.

\section{Microbial Degradation of Polythene under Laboratory Condition:}

Liquid culture method (Orhan et al., 2004):

The pre-weighed strips of polythene bags were aseptically transferred into the conical flask containing $100 \mathrm{ml}$ of nutrients broth and then inoculated with identified polythene degrading microflora and the another conical falsk inoculated with consortia of this microflora to observed the plastic degradation capasity of microflora. These flasks were inoculated at $37^{\circ} \mathrm{C}$ for 10,20 and 30 days. After a period of time, the strips were washed in $70 \%$ ethanol, air dried and weighed to check the final weight. Finally the weight loss was calculated and compared on the below formula

weight loss $(\%)=($ Initial weight - Final weight $) \times 100$

$$
\text { Initial weight }
$$

\section{RESULTS AND DISCUSSION}

Biodiversity and occurrence of polythene degrading microorganism vary depending on the environment, such as soil, sea compost, activated sludge, etc. It is necessary to investigate the distribution and population of polymerdegrading microorganism in various ecosystem. Generally, the adherence of microorganisms on the surface of plastic followed by the colonization of the exposed in the microbial degradation of plastic. 
Table 1 : Frequency distribution of Microbial

Diversity Obtained from collected samples

\begin{tabular}{|c|c|c|c|}
\hline $\begin{array}{c}\text { Sr } \\
\text { no }\end{array}$ & Isolates & $\begin{array}{c}\text { Frequency } \\
\text { distributio } \\
\mathrm{n}\end{array}$ & $\begin{array}{c}\text { Percentage } \\
\%\end{array}$ \\
\hline 1 & P.aeruginosa, & 4 & $90 \%$ \\
\hline 2 & $\begin{array}{c}\text { Streptococcus.pyoge } \\
\text { nes }\end{array}$ & 2 & $45 \%$ \\
\hline 3 & S.aureus & 4 & $90 \%$ \\
\hline 4 & E.coli & 3 & $67.5 \%$ \\
\hline 5 & Bacillus. subtilis & 3 & $67.5 \%$ \\
\hline
\end{tabular}

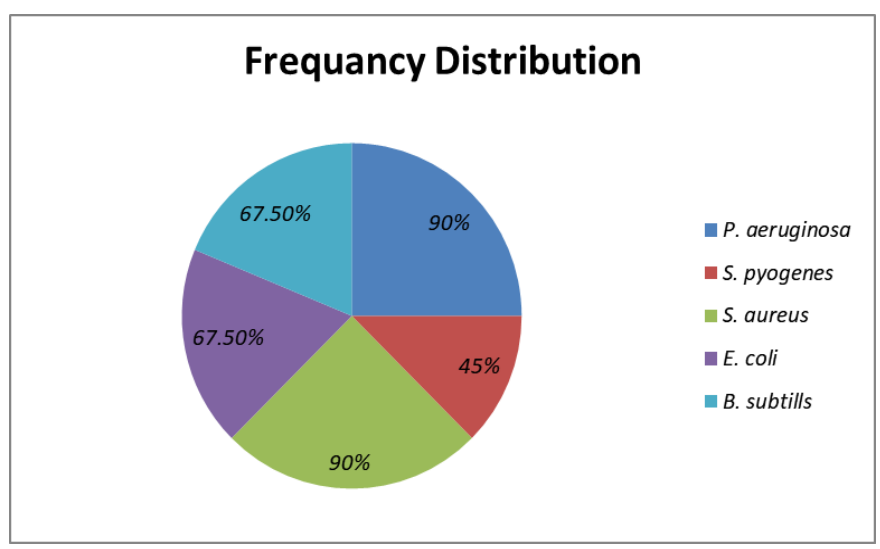

Fig 1 : Frequency distribution of Microbial Diversity Obtained from collected samples - Pie chart

\begin{tabular}{|c|c|c|c|c|}
\hline Microorganisms & $\begin{array}{c}\text { Initial } \\
\text { weight } \\
(\mathrm{gm})\end{array}$ & $\begin{array}{c}\text { Final } \\
\text { weight } \\
(\mathrm{gm})\end{array}$ & $\begin{array}{c}\text { Total } \\
\text { loss of } \\
\text { weight } \\
(\mathrm{gm})\end{array}$ & $\begin{array}{c}\text { \% loss } \\
\text { in } \\
\text { weight }\end{array}$ \\
\hline P.aeruginosa & 0.0335 & 0.0323 & 0.0012 & 6.15 \\
\hline S.aureus & 0.0312 & 0.0300 & 0.0012 & 3.84 \\
\hline E.coli & 0.0322 & 0.0321 & 0.0001 & 0.310 \\
\hline B.subtilis & 0.0321 & 0.0310 & 0.0011 & 3.42 \\
\hline S.pyogenes & 0.0320 & 0.0319 & 0.0001 & 0.312 \\
\hline
\end{tabular}

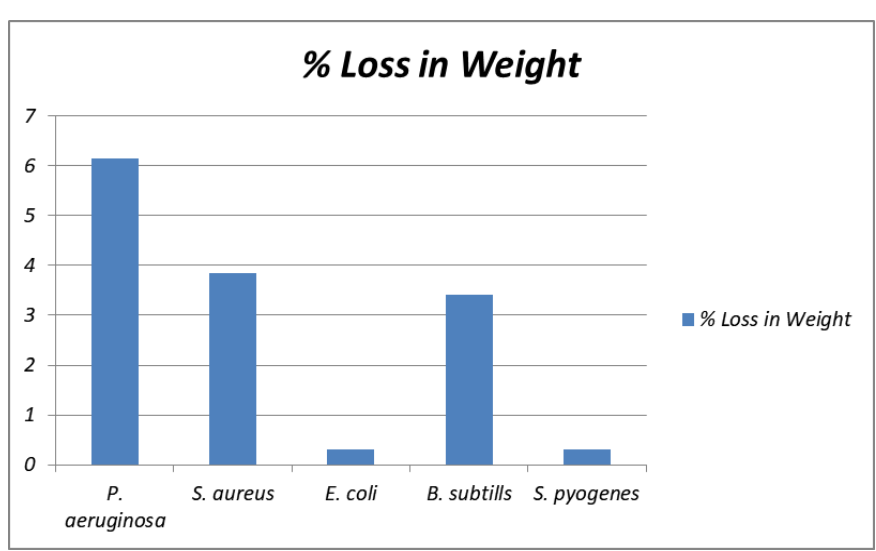

Fig 2: Percentage loss in weight of polythene by the isolated Microflora: Bar diagram.

Table 3 : \% Loss in weight of polythene by the Consortial Microflora

\begin{tabular}{|c|c|c|c|c|}
\hline Microorganisms & $\begin{array}{c}\text { Initial } \\
\text { weight } \\
(\mathrm{gm})\end{array}$ & $\begin{array}{c}\text { Final } \\
\text { weight } \\
(\mathrm{gm})\end{array}$ & $\begin{array}{c}\text { Total } \\
\text { loss of } \\
\text { weight } \\
(\mathrm{gm})\end{array}$ & $\begin{array}{c}\% \text { loss } \\
\text { in } \\
\text { weight }\end{array}$ \\
\hline $\begin{array}{c}\text { S.aureus }+ \\
\text { Bacillus subtilis }\end{array}$ & 0.0320 & 0.0319 & 0.0001 & 0.31 \\
\hline $\begin{array}{c}\text { S.aureus }+S . \\
\text { pyogenes }\end{array}$ & 0.0350 & 0.0341 & 0.0009 & 0.28 \\
\hline $\begin{array}{c}\text { E. coli+ } \\
\text { P.aeruginosa }\end{array}$ & 0.0320 & 0.0310 & 0.001 & 3.125 \\
\hline
\end{tabular}

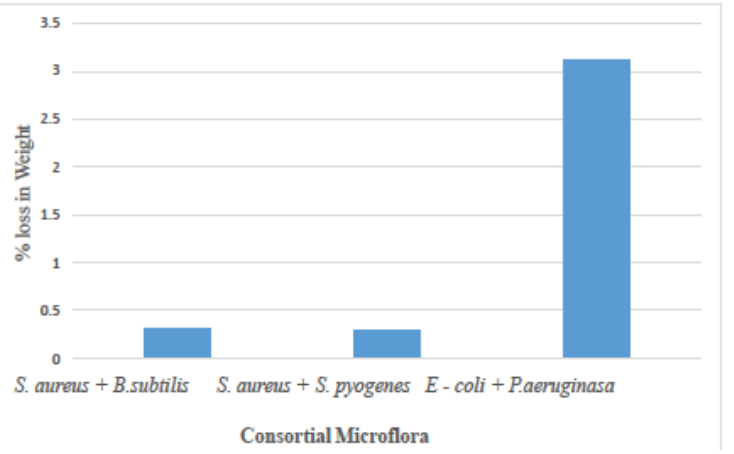

Fig 3: Percentage loss in weight of polythene by the consortial Microflora: Bar diagram 


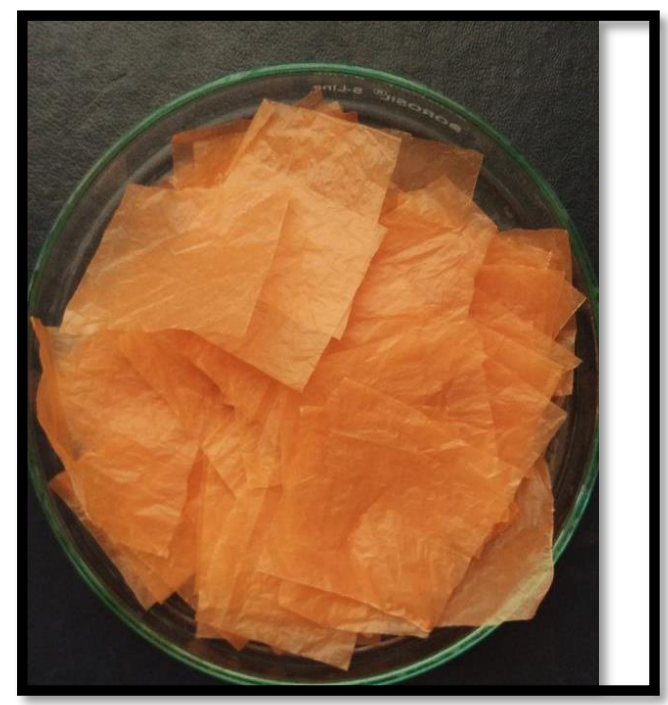

Polythene bags pieces.

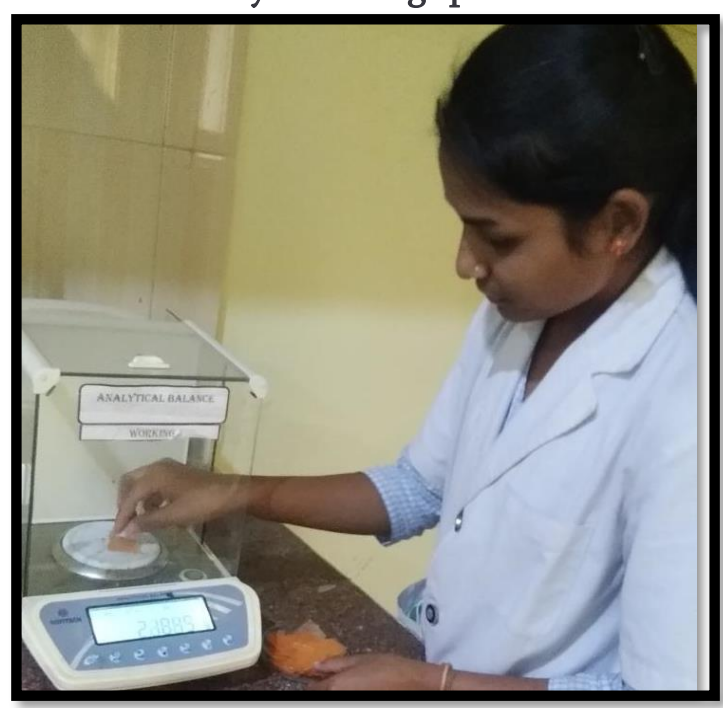

Photograph of Polythene weighing

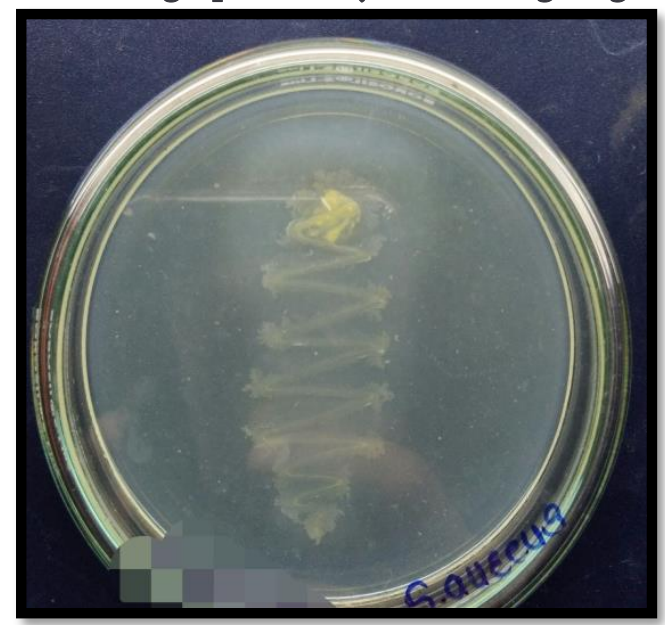

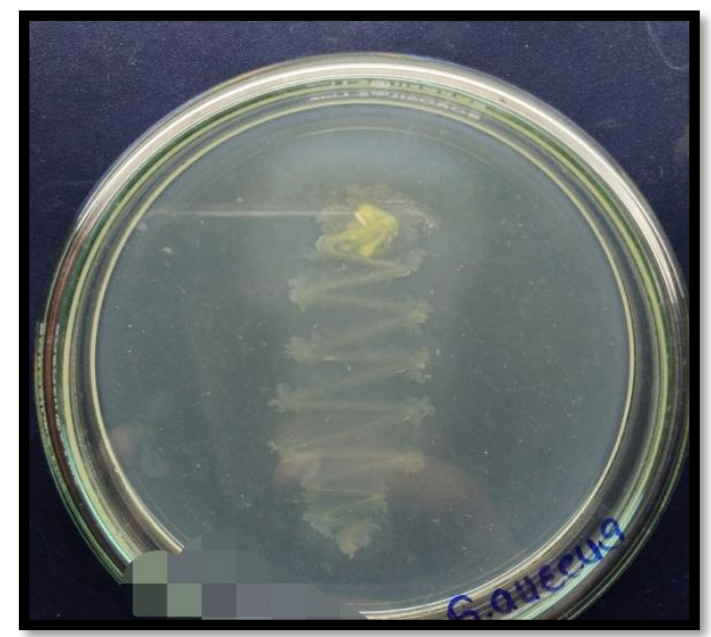

Clear zone formation around the colony on Mineral salt agar
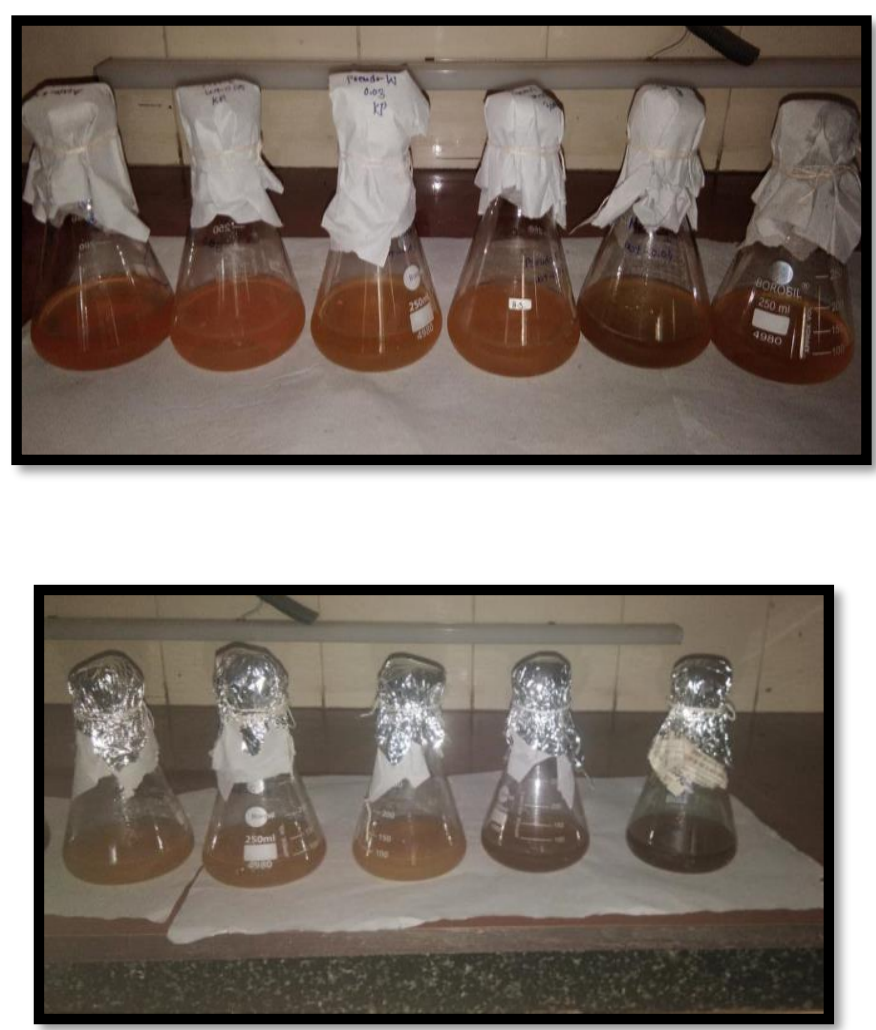

Biodegradation of Polythene by Flask Method

The present study was aimed to investigate bacterial strain from the plastic contaminated Garbage soil with the ultimate objective of plastic degradation. The sample was collected and studied for its microbial diversity. Microbial diversity observed was 
P.aeruginosa, Streptococcus pyogenes, S.aureus, E.Coli. Bacillus subtilis.

The soil sample were Collected from the plastic contaminated Garbage soil from the various sites i.e. Akot file, Malkapur, Ramdas peth, khadaki of Akola district. The four soil sample were Collected from the plastic contaminated Garbage soil from the various sites i.e. Akot file, Malkapur, Ramdas peth, khadaki of Akola district.The soil sample were inoculated on various selective media, identified \& confirmed on the basis of Bergeys Manual of Determinative Bacteriology. All the isolated bacterial were screen qualitatively for the production of different enzymes such as, Oxidase, Catalase, Gelatinase, Amylase, Urease.

Similar study was reported by Okoh and Atuanya (2014) they reported that Pseudomonas sp. Possesses greater potential to degrade polyethylene compared to other bacteria and fungi. Deepika and Jaya Madhuri (2015) also concluded that Pseudomonas sp. have significant plastic degradation capacity and it degrade up to $24.22 \%$ for the period of 6 months. Similarly, Kyaw et al., (2012) studied that biodegradation of Low Density Polyethylene (LDPE) by Pseudomonas sp.They reported that after 120 days of incubation period, the percentage of weight reduction was $20 \%$ in Pseudomonas aeruginosa (PAO1) strain, $11 \%$ in Pseudomonas aeruginosa (ATCC) strain, 9\%in Pseudomonas putida and 11.3\% in Pseudomonas syringae strain.

The polythene containing mineral salt agar plates were inoculated with the isolated bacteria. All the isolates were screened for their degradation activity. Clear zone was observed after 10 days of incubation at $25-30^{\circ} \mathrm{C}$ around the colony. On this screening Pseudomonas sp, Bacillus sp,Streptococcus sp, staphylococcus $s p$, and $E$ coli showed high degradation activity. Similar type of findings were reported by Kathiresan K., (2003) this species of microoganism are associated with the polythene bags and plastic films in soil. Further these soil microorganisms were reported to have the ability for degrading plastics. However the strains with high degradation activity were selected for fermentation.

Determination of weight loss by selected microorganisms were further tested in the laboratory condition to check the ability of degrading polythene and plastics. The bacteria separately allowed to degrade the polythene and plastic incubated for 1 months. After the1 months period the strips were collected, washed throughly using distilled water, shade dried and then weighted to check the final weight. These microorganisms utilize polythene film as a sole source of carbon resulting in partial degradation of plastics. They colonize on the surface of the polyethylene films or plastic cups forming a biofilm. Cell surface hydrophobicity of these organisms was found to be an important factor in the formation of biofilm on the polythene surface, which consequently enhanced biodegradation of the polymers.

Kathiresan and Bingham(2001) reported that bacteria caused the biodegradation ranging from 2.19 to $20.54 \%$ for polythene and 0.56 to $8.16 \%$ for plastics. Among all the species, Aspergillus glaucus was more active than A.niger in degrading $28.8 \%$ of polythene and $7.26 \%$ of plastics within a month. This may be attributed to the thickness of the polythene that is 5times thinner than the plastics. Once the organisms get attached to the surface, it. starts growing by using the polymer as the carbon source. In the primary degradation, the main chain cleaves leading to the formation of low-molecular weight fragments (oligomers), dimers or monomers (Vasile, C., 1993).The degradation due to the extracellular enzymes secreted by the organisms. These low molecular weight compounds are further utilized by the microbes as carbon and energy sources.The 
resultant breakdown fragments must be completely used by the microorganisms, otherwise there is the potential for environmental and health consequences (Narayan, R., 2006).

As per the result of study the naturally growing soil microflora like P.aeruginosa, $S$. aureus, $E$ coli, $S$. pyogenes, $B$. subtilis shows great efficiency in degradation of plastic. $P$. aeruginosa shows maximum percentage loss in the reduction of polythene $(6.15 \%)$ and $E$. coli shows minimum percentage loss in the reduction of polythene as $(0.310 \%)$ compared to isolated microflora i.e the $P$. aeruginosa have a higher degrading effectiveness under laboratory condition. Also we are utilized the consortia of the two different organisms such as $E$. coli $+P$. aeruginosa, S.aureus $+S$. Pyogenes, S.aureus+ B. subtilis to study the degrading efficiency of of isolate, maximum activity was observed in case of consortial organisms i.e. $E$ coli $+P$. aeruginosa $(3.125 \%)$ results were presented in Table No.1 and Table No. 2 and Graphically represented in Fig. No.1 and Fig. No. 2.

\section{CONCLUSION}

The Isolated microbes were native to the site of polyethylene disposal and might show some degradability in natural conditions, yet they also exhibited biodegradation in laboratory conditions on synthetic media. This gives some suggestion that these microbes can be used in both natural and artificial conditions for the purpose of degradation of polymers. Our knowledge, microbes cause greatest degradation of polythene and plastics. Among the microbes Pseudomonas aeruginosa having greater degradation ability as compared to S.aureus, Bacillus subtilis, $S$. pyogenes, E.coli. Hence, the further attention is required from microbiologists for commercial degradation and eco-friendly polyethylene with Pseudomonas aeruginosa.

\section{REFERENCES}

[1]. Albertsson, A.C., Andersson, S.O., \& Karlsson, S. (1987).The mechanism of biodegradation of Polyethylene, Polymer Degradation and Stability, $\quad 18, \quad 73-87$ doi:http:/ldx.doi.org/10.1016/0141-3910(87) 90084- $\mathrm{x}$

[2]. Augusta, J., Müller, R.J. and H. Widdecke, 1993.A. rapid evaluation plate-test for the biodegradabilityof plastics. Appl. Microbiol. Biotechnol., 39: 673-678

[3]. Chiellini E., Corti A.,Swift G, Biodegradation of thermally -oxidized. fragmented low density polyethylenes. Polym. Degradability. Stab. 81(2) (2003) 341-351,doi:http://dx. doi.org/10.1016/S0141-3910(03)00105-8.

[4]. Deepika, S., Jaya Madhuri, R. 2015.Biodegradation of Low density polyethylene by microorganism from garbage soil. J. Explain. Biol. Agricultural science, 3(1):15-21.

[5]. Denuncio P, Bastida R, Dassis M, Giardino G, Gerpe M, et al. (2011) Plastic ingestion in Franciscana dolphins, Pontoporia blainvillei (Gervais and d0Orbigny, 1844), from Argentina. Mar Pollut Bull.3:25-30.

[6]. Holt, J.G.,Krieg N.R., Sneath P.H.A., staley J.T. and Williams S.T., 1994. Gram-Positive Cocci. In: Bergey's Manual of Determinative Microbiology, Hensyl, W.R. (Ed.). 9th Edn., Williams and Wilkins,Baltimore, USA., pp: 527-558.

[7]. Kathiresan K., Polythene and Plasticsdegrading microbes from the mangrove. soil, Rev. Biol. Trop., 51(3), 629-634 (2003)28)Kim M (2003) Evaluation of degradability of hydroxypropylated potato starch/polyethylene films. Carbohydr Polym 54(2):173-181. 
[8]. Kathiresan, K. and B.L. Bingham, 2001. Biology of mangroves and mangrove ecosystems. AdvancesMar. Biol., 40: 81-251

[9]. Koutny M, Sancelme M, Dabin C, Pichon N, Delort A-M, Lemaire J. Acquired biodegradability of polyethylenes containing pro-oxidant additives. Polymer Degradation and Stability. 2006; 91(7): 1495-1503. doi: 10.1016/j.polymdegradstab.2005.10.007

[10]. Kumar, S., Sad, P.M., Rebecca, L.J.and Sharmila, S.(2013). Isolation and Identification of LDPE degrading fungi from municipal solid waste. Journal of Chemical and Pharmaceuticals Research. 5(3):78-81.

[11]. Kyaw, B. M., Champakalakshmi, R., Sakharkar, M. K., kim,. $\quad$ C.S.,sakharkar K.R.,2012.Biodegradation of Low density polyethylene (LDPE) by Pseudomonas species Indian J. Microbiol., 52(3):411-419

[12]. Narayan, R., 2006. Biobased and biodegradable polymer materials: rationale, drivers and technology exemplars. American Chemical Society Symposium Ser., 939(18): 282

[13]. Okoh, E. B. and Atuanya, E. I. (2014) Impacts of soil composting and poultry manure on biodegradation of polyethylene. International J. Appl. Micro. Biotech. Results. (IJAMBR) 2: 1829 ISSN 2053-1818.

[14]. Orhan, Y., J. Hrenovic and H. Buyukgungor, 2004.Biodegradation of plastic compost bags under controlled soil conditions. Acta Chim. Slov.51: 579-588.50)Orr IG, Hadar Y, Sivan A. Colonization, biofilm formation and biodegradation of polyethylene by a strain of Rhodococcus ruber. Appl Microbiol Biotechnol. 2004; 65(1): 97-104. doi: 10.1007/s00253-0041584-8

[15]. Roy P.K, Surekha P, Tulsi E, Deshmukh C, Rajagopal C (2008) Degradation of abiotically aged LDPE films containing pro-oxidant by bacterial consortium. Polym Degrad Stab 93:1917-1922.

[16]. Shimao M. Biodegradation of plastics. Current Opinion in Biotechnology, 2001; 12: 242-247. https://doi.org/10.1016/S0958-1669(00)00206-8 PMID: 1140410165)

[17]. Spear L.B, Ainley D.G, Ribic C.A (1995) Incidence of plastic in seabirds from the tropical pacific 1984-1991: Relation with distribution of species, sex, age, season, year and body weight. Mar Environ Res 40: 123-146.

[18]. Vasile, C., 1993. Degradation and decomposition, in 22. Oskay , M., A.U. Tamer and C. Azeri, 2004. African Handbook of polyolefins synthesis andproperties, J. Biotechnol., 3(9): 441- 446. edited by C Vasile and R B Seymour (Marcel Dekker Inc, New York)., pp: 479-509.

\section{Cite this article as :}

Kalyani P. Patinge, S. N. Zodpe, "Screening of Low Density Polyethylene Degrading Microflora From Garbage Soil", International Journal of Scientific Research in Science and Technology (IJSRST), Online ISSN : 2395-602X, Print ISSN : 2395-6011, Volume 7 Issue 4, pp. 110-116, July-August 2020. Available at doi $\quad$ : https://doi.org/10.32628/IJSRST207435 Journal URL : http://ijsrst.com/IJSRST207435 